\title{
COMPARATIVE STUDIES ON THE WEAR OF ADI ALLOY CAST IRONS AS WELL AS SELECTED STEELS AND SURFACE-HARDENED ALLOY CAST STEELS IN THE PRESENCE OF ABRASIVE
}

\begin{abstract}
The paper presents the results of wear tests obtained for 4 groups of materials: surface-hardened alloy steels and alloy cast steels for structural applications, hard-wearing surface-hardened alloy cast steels, and austempered alloy cast irons. The wear tests have been performed on a specially designed test rig that allows reproducing the real operating conditions of chain wheels, including the rolling and sliding form of contact between elements. The chain wheels subjected to tests were operated with the use of loose quartz abrasive. This study presents results of measurements of material parameters, micro-structure of a surface subject to wear, as well as the linear wear determined for the materials considered. Based on the results, the following was found: the best wear properties were obtained for surface-hardened alloy steels and wear surface; strengthening of the ADI surface took place - most probably as a result of transformation of austenite into martensite; the uniformity of the structure of the materials affects the surface wear process. The study also indicated a significant degree of graphite deformation in ADI characterized by the upper ausferritic structure and its oblique orientation in relation to the surface, which resulted in a facilitated degradation of the surface caused by the quartz abrasive.
\end{abstract}

Keywords: austempered ductile iron, steel, steel cast, wear, abrasion

\section{Introduction}

Materials that optimally combine high strength, wear and plastic properties with simultaneous economics of the manufacturing process have been sought for many years [1-5]. The materials that can meet these requirements are austempered ductile irons (ADI). ADI are obtained from nodular cast irons with a specific chemical composition that are subjected to austempering and isothermal quenching. As a result of these processes, ausferritic structure with unique properties is obtained [6] - especially when compared to alloy steels and alloy cast steels.

Rimmer and Bromwich [7] mention the following advantages of ADI:

a. Excellent castability - complex shapes of workpieces can be easily obtained using casting methods.

b. Lower costs of processing - as compared with steel, nodular irons are more easily treatable before the isothermal treatment, which allows reducing the costs of roughing.

c. Lower costs of heat treatment - the cost of heat treatment of ADI castings is usually lower as compared with carburizing or induction hardening used in relation to steels.

d. Lower energy consumption - the energy consumption associated with a typical ADI casting is lower by $50 \%$ as compared with that connected with casting of cast steel and by $80 \%$ in comparison with forging of steel. e. Increased productivity - due to very good casting properties, making workpieces of ADI is more efficient as compared with the forging and carburizing processes used in the case of alloy steels.

f. High strength - strength parameters of austempered cast iron are comparable with those of steel.

g. Lower specific gravity as compared with that of steel this allows reducing the weight of workpieces without any reduction in the safety of the construction.

h. A possible reduction of the mass as compared with aluminium workpieces - due to a significantly higher strength of ADI, it is possible to optimize the shape and mass of the product.

i. Improved vibration dampening properties - graphite content in the matrix causes that workpieces produced from ADI generate less vibrations and noise.

j. High-wear properties - Resistance of ADI to abrasion usually exceeds the resistance of the structural and tool steels used for elements exposed to abrasive wear.

Especially the latter of these benefits is important when increasing the durability of equipment exposed to abrasive action of the abrasive. The steels and cast steels used so far are not always can meet the requirements for elements of equipment operated in harsh conditions. Even surface-hardened forged steels with high strength cannot guarantee the assumed service life. This is 
particularly important in the case of the declared guarantee for failure-free operation of machinery and equipment. It should be noted that in addition to the predominant form of destruction, the operation of machines is often accompanied by other destructive processes that may have a synergistic effect and intensify the wear of machine components and assemblies.

A large number of scientific studies on wear properties of cast irons subjected to isothermal treatment can be found in the available literature. Among them it is worth to mention the work by Fordyce and Allen [8], in which it has been determined that the resistance of austempered cast irons to abrasive wear is the same as in the case of steel with a high surface hardness. In addition, Nili Ahmadabadi et al. in [9] have found that the abrasion resistance of ADI is 2.5 times higher than that of grey cast iron in pearlitic matrix that contains phosphorus. The authors explained that the higher wear resistance of ADI results from the properties of the ausferritic structure containing bainitic ferrite and retained austenite. However, Liu Ping and Bahadur [10] compared the wear resistance of steel with the same structure as that of the ADI matrix and ADI itself - they found that the steel had a higher resistance. They substantiated this fact by a low resistance of graphite to microcutting and by propagation of microcracks from spots formed after the destruction of the graphite nodules. Myszka and Wieczorek [11] performed wear tests for 34CrNiMo6 hardened steel and three types of austempered ductile iron containing Mo and $\mathrm{Ni}$. Wear tests showed that the cast iron had properties comparable to those of the steel tested and that the wear resistance of ADI was increasing along with an increase in the nominal load. Hayrynen et al. [12] found a significant reduction in the abrasive wear of ADI as compared with carbon steels with a hardness of $40 \mathrm{HRC}$.

The authors dealing with the problems associated with wear properties of ADI emphasise unanimously the importance of phase transitions resulting from mechanical loads. Mechanical instability of austenite at the ambient temperature is similar to the characteristics of austenite in TRIP (TRansformation Induced Plasticity) steel. TRIP is a transformation of austenite into deformation-induced martensite caused by an increase in the stress or strain [13]. In particular, Haseeb et al. [14] proved that the TRIP mechanism was responsible for the wear resistance of ADI. Schissler et al. [15] and Owhadi et al. [16] found that a low content of martensite in the microstructure (at a level of $0.1 \%$, which had been formed as a result of the austenite transformation, had a positive impact on wear properties of cast irons. Myszka and Wieczorek [17] after having performed wear tests of three types of nodular cast iron with addition of $\mathrm{Cu}$ and $\mathrm{Ni}$ in corundum abrasive have found that the hardest cast iron has the best wear resistance, but strengthening of the surface apparently occurs in the material with the lowest hardness and best ductility that contained the highest amount of retained austenite.

An attempt was made in this study to compare in the quantitative and qualitative terms the wear properties of the austempered ductile irons with those of typical steels and cast steels intended for operation in harsh conditions. However, the method of carrying out the tests differed significantly in relation to the method with which the test results described above were obtained. At the stage of building the test rig it has been assumed that the tests will be performed in conditions similar to real operating conditions and rolling-sliding motion of the elements. A complex form of the loading conditions characterized by the presence of rolling-sliding motion and the stochastic load changes could have affect significantly the resistance of materials to the destructive action of the quartz abrasive.

\section{Experimental details}

\subsection{Characteristics of the materials tested}

The materials to be used for the tests of wear properties can be divided into 4 groups:

A. Alloy tool steels for quenching and tempering (used for the most responsible applications in elements exposed to abrasive wear):

- 42CrMo4,

- 34CrNiMo6.

B. Hard-wearing alloy cast steels (also used for responsible applications in elements exposed to abrasive wear):

- GS42CrMo4

- L35GSM (30CrMo12),

- 20HGSNM,

C. Structural alloy cast steels (these materials are typically used for elements that are subjected to abrasive wear only periodically and are not required to have a high wear resistance):

- A6 (1.5065),

- L30GS (30Mn5),

D. Austempered ductile irons (materials considered for elements of devices working in conditions of considerable abrasive wear):

- EN-GJS-800-8 acc. to EN 1564:1997 [18] (designation in the paper-ADI_360),

- EN-GJS-1000-5 acc. to EN 1564:1997 (designation ADI_310),

- EN-GJS-1200-2 acc. to EN 1564:1997 (designation ADI_270),

- EN-GJS-1400-1 acc. to EN 1564:1997 (designation ADI_240).

Chemical compositions of the steels and cast steels tested were given in Table 1, the heat treatment conditions - in Table 3, while mechanical properties - in Table 5.

The chain wheels tested - made of $42 \mathrm{CrMo} 4$ and $34 \mathrm{CrN}-$ iMo6 steels from a toughened forged rod using machining methods. The final process operation was surface hardening. The GS42CrMo 4, L35GSM, L30GS, 20HGSNM and A6 cast steels were cast in sand moulds and subjected to normalization and toughening. After the final machining, the chain wheels were also subjected to surface hardening. 
The surface hardening was performed using the flame method; the machined surfaces were heated to the temperature of approx. $800^{\circ} \mathrm{C}$, and then cooled in $6 \%$ solution of a water and polymer coolant [19].

Ductile iron EN-GJS-600-3 (PN-EN 1563) with the chemical composition shown in Table 2 was used for the wear testing. The ductile iron castings had a pearlitic-ferritic structure, a nodule count of 200 graphite nodules per $\mathrm{mm}^{2}$ and graphite nodularity greater than $90 \%$.

After the machining, the chain wheels made of nodular cast iron were subjected to isothermal treatment. The parameters of the austempering and isothermal quenching processes were selected on the basis of previously conducted studies $[11,17,20]$. The list of the process parameters is shown in Table 4, while mechanical properties in Table 5 .

TABLE 1

Chemical composition of steel and cast steel [mass\%]

\begin{tabular}{|c|c|c|c|c|c|c|}
\hline \hline Designation & $\mathbf{C}$ & $\mathbf{S i}$ & $\mathbf{M n}$ & $\mathbf{C r}$ & $\mathbf{N i}$ & Mo \\
\hline 42CrMo4 & 0,41 & 0,23 & 0,83 & 1,1 & 0,07 & 0,18 \\
\hline 34CrNiMo6 & 0,377 & 0,269 & 0,602 & 1,01 & 0,952 & 0,194 \\
\hline GS42CrMo4 & 0,35 & 0,38 & 0,72 & 1,21 & 0,06 & 0,5 \\
\hline L35GSM & 0,36 & 0,67 & 1,27 & - & - & 0,036 \\
\hline 20HGSNM & 0,22 & 0,82 & 0,91 & 0,78 & 0,95 & 0,16 \\
\hline L30GS & 0,28 & 0,636 & 1,27 & 0,096 & 0,106 & - \\
\hline A6 & 0,295 & 0,52 & 1,295 & - & - & - \\
\hline
\end{tabular}

TABLE 2

Chemical composition of ductile iron EN-GJS-600 [mass\%]

\begin{tabular}{|c|c|c|c|c|c|}
\hline \hline \multirow{4}{*}{ ADI } & $\mathbf{C}$ & $\mathbf{S i}$ & $\mathbf{M n}$ & $\mathbf{S}$ & $\mathbf{P}$ \\
\cline { 2 - 6 } & 3,50 & 2,54 & 0,16 & 0,013 & 0,041 \\
\cline { 2 - 6 } & $\mathrm{Mg}$ & $\mathrm{Cr}$ & $\mathrm{Cu}$ & $\mathrm{Ni}$ & $\mathrm{Mo}$ \\
\cline { 2 - 6 } & 0,047 & 0,026 & 0,50 & 1,40 & 0,24 \\
\hline
\end{tabular}

TABLE 3

The process parameters used for the production of steel and steel cast chain wheels

\begin{tabular}{|l|c|c|c|c|}
\hline \hline $\begin{array}{c}\text { Heat treatment } \\
\text { parameters }\end{array}$ & 42CrMo4 & 34CrNiMo & GS42CrMo4 \\
\hline $\begin{array}{l}\text { Austenitising } \\
\text { temperature, }{ }^{\circ} \mathrm{C}\end{array}$ & \multicolumn{3}{|c|}{860} \\
\hline $\begin{array}{l}\text { Austenitising } \\
\text { time, min }\end{array}$ & \multicolumn{3}{|c|}{120} \\
\hline $\begin{array}{l}\text { Tempering } \\
\text { temperature, }{ }^{\circ} \mathrm{C}\end{array}$ & \multicolumn{3}{|c|}{600} & A6 \\
\hline $\begin{array}{l}\text { Heat treatment } \\
\text { parameters }\end{array}$ & LS5GSM & L20HGSNM & L30GS & 600 \\
\hline $\begin{array}{l}\text { Tempering } \\
\text { temperature, }{ }^{\circ} \mathrm{C}\end{array}$ & 550 & 550 & 600 & 600 \\
\hline $\begin{array}{l}\text { Austenitising } \\
\text { temperature, }{ }^{\circ} \mathrm{C}\end{array}$ & \multicolumn{3}{|c|}{860} \\
\hline $\begin{array}{l}\text { Austenitising } \\
\text { time, min }\end{array}$ & \multicolumn{3}{|c|}{120} \\
\hline
\end{tabular}

TABLE 4

The process parameters used for the production of ADI chain wheels

\begin{tabular}{|l|c|c|c|c|}
\hline \hline \multicolumn{1}{|c|}{$\begin{array}{c}\text { Heat treatment } \\
\text { parameters }\end{array}$} & ADI_240 & ADI_270 & ADI_310 & ADI_360 \\
\hline $\begin{array}{l}\text { Austempering } \\
\text { temperature, }{ }^{\circ} \mathrm{C}\end{array}$ & 240 & 270 & 310 & 360 \\
\hline $\begin{array}{l}\text { Austempering } \\
\text { time, min }\end{array}$ & \multicolumn{3}{|c|}{150} \\
\hline $\begin{array}{l}\text { Austenitising } \\
\text { temperature, }{ }^{\circ} \mathrm{C}\end{array}$ & \multicolumn{3}{|c|}{950} \\
\hline $\begin{array}{l}\text { Austenitising } \\
\text { time, min }\end{array}$ & \multicolumn{3}{|c|}{180} \\
\hline
\end{tabular}

TABLE 5

Mechanical properties of the tested steels, steel casts and ADI (measurement uncertainty determined for $f=N-1=4$ and $\alpha=0,05)$

\begin{tabular}{|c|c|c|c|}
\hline Mechanical Properties & 42CrMo4 & 34CrNiMo & GS42CrNiMo4 \\
\hline Tensile Strength TS, MPa & $930 \pm 3,6$ & $1030 \pm 3,8$ & $1115 \pm 3,8$ \\
\hline Yield Strength YS, MPa & $895 \pm 3,6$ & $880 \pm 3,7$ & $905 \pm 3,6$ \\
\hline Impact Toughness K, J & $127 \pm 1,1$ & $70 \pm 1,1$ & - \\
\hline Elongation A5, \% & $17,5 \pm 0,1$ & $10 \pm 0,1$ & $8,9 \pm 0,1$ \\
\hline Mechanical Properties & L20HGSNM & L30GS & A6 \\
\hline Tensile Strength TS, MPa & $1134 \pm 4,0$ & $631,8 \pm 3,1$ & $739 \pm 3,8$ \\
\hline Yield Strength YS, MPa & $1083 \pm 3,8$ & $396 \pm 3,0$ & $526 \pm 3,4$ \\
\hline Impact Toughness K, J & - & $46,2 \pm 1,1$ & $33,5 \pm 1,1$ \\
\hline Elongation A5, \% & $10,0 \pm 0,1$ & $17,8 \pm 0,1$ & $16,3 \pm 0,1$ \\
\hline Mechanical Properties & LS5GSM & ADI_240 & ADI_270 \\
\hline Tensile Strength TS, MPa & $1152 \pm 3,7$ & $1507 \pm 4,6$ & $1372 \pm 4,8$ \\
\hline Yield Strength YS, MPa & $891 \pm 3,7$ & $1072 \pm 4,4$ & $936 \pm 4,5$ \\
\hline Impact Toughness K, J & $19,8 \pm 1,1$ & $54 \pm 1,1$ & $72 \pm 1,1$ \\
\hline Elongation A5, \% & $8,7 \pm 0,1$ & $3 \pm 0,1$ & $4 \pm 0,1$ \\
\hline Mechanical Properties & ADI_310 & & ADI_360 \\
\hline Tensile Strength TS, MPa & $1132,0 \pm 3,9$ & & $1028,1 \pm 3,8$ \\
\hline Yield Strength YS, MPa & $804,2 \pm 3,6$ & & $652,0 \pm 3,9$ \\
\hline Impact Toughness K, J & $84 \pm 1,1$ & & $124 \pm 1,1$ \\
\hline Elongation A5, \% & $5 \pm 0,1$ & & $10 \pm 0,1$ \\
\hline
\end{tabular}

\subsection{Test rig and methodology}

Tests of wear properties of the ferrous alloys investigated were carried out on a test rig that allows reproducing the real operating conditions of chain wheels. The view and diagram of the test rig are shown in Fig. 1A and Fig. 1B, respectively. The main wear tests carried out in the presence of loose quartz abrasive (Fig. 1C) lasted in total 100 hours for each direction of motor rotations. The presence of the abrasive between the mating surfaces of the chain wheels and the chain was ensured by filling the test box with quartz abrasive.

The tangential velocity of the chain wheels was $v=0.7 \mathrm{~m} / \mathrm{s}$. The power consumed by each motor was $P_{M 1}=P_{M 2}=7.5 \mathrm{~kW}$.

Taking into account the measured power of the motors, the FEM method was used to determine the surface pressures between the surface of the chain wheel and the chain (48.9 MPa) and the maximum reduced stresses $(2.18 \mathrm{MPa})$. 
A)

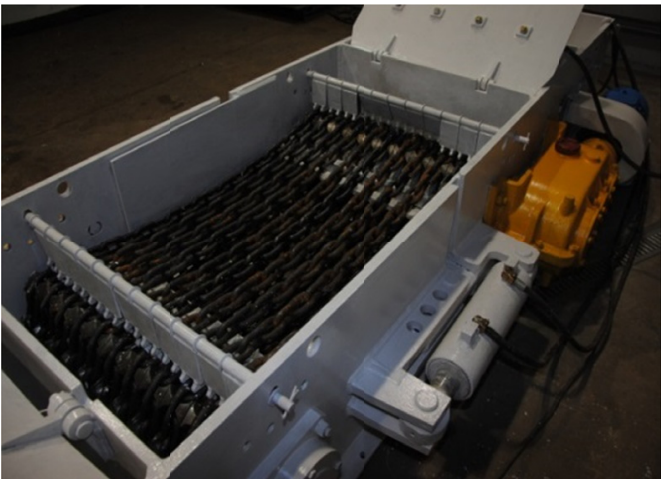

B)

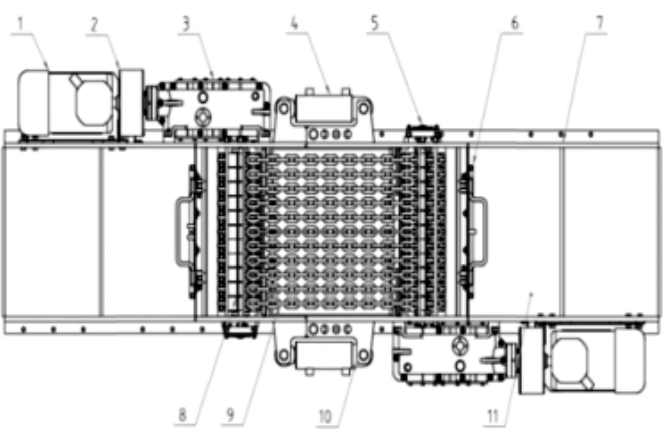

C)

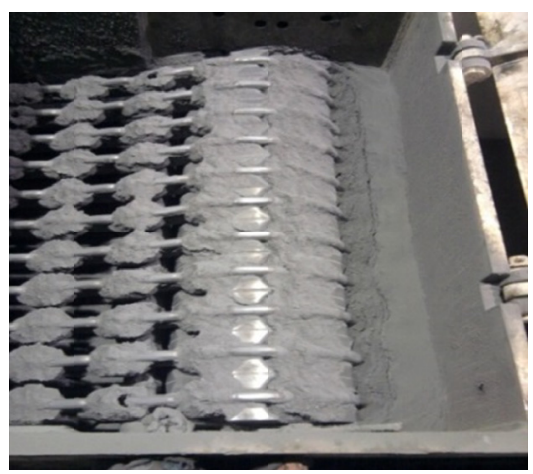

Fig. 1. The test rig, A. View, B. Diagram, C. The chain wheels during the tests; designations: 1 - Induction motor $22 \mathrm{~kW}, 2$ - Flexible coupling, 3 -Conical - cylindrical reduction gear, 4 - Hydraulic cylinder, 5 - Axle shaft, 6 - Sprinkler system for the test chamber, 7 - Body of the test rig, 8-Test samples, 9-Chain, 10-Mounting bracket of the hydraulic cylinder, 11 - Additional chamber for aggregate

In order to determine the wear of the surface, the geometry of 24 mating areas of all chain wheels used in a given test cycle was measured with the Zeiss Acura measuring machine prior to starting the main tests.

During the measurement, approx. 300 points along the predefined route of the tip of the machine's measuring head were read and recorded. 10 basic lines can be identified in this route (Fig. 2). After the completion of the wear tests, measurements of mating surfaces of the chain wheels were performed again.

The linear wear $\delta_{i}$ of a single measuring point is determined by the equation (1):

$$
\delta_{i}=\sqrt{\left(x_{i, 1}-x_{i, 2}\right)^{2}+\left(y_{i, 1}-y_{i, 2}\right)^{2}+\left(z_{i, 1}-z_{i, 2}\right)^{2}}
$$

where:

$x_{i, 1}-x$ coordinate of the $i$-th point before the test,

$x_{i, 2}-x$ coordinate of the $i$-th point after the test, $y_{i, 1}-y$ coordinate of the $i$-th point before the test,

$y_{i, 2}-y$ coordinate of the $i$-th point after the test,

$z_{i, 1}-z$ coordinate of the $i$-th point before the test,

$z_{i, 2}-z$ coordinate of the $i$-th point after the test.

The maximum value of the wear of the surface tested $\delta_{i, \mathrm{MAX}}$ is determined by the equation (2):

$$
\delta_{i, \mathrm{MAX}}=\operatorname{Max}\left\{\delta_{i}\right\}
$$

The $\delta_{A V R}$ MAX value was adopted as a measure of abrasive wear. It is the average of all $24 \delta_{i, \mathrm{MAX}}$ values for a given chain wheel. This parameter is determined by the equation (3):

$$
\delta_{A V R_{-} \mathrm{MAX}}=\frac{\sum_{1}^{n} \delta_{i, \mathrm{MAX}}}{n}
$$

where $n$ - the number of seat surfaces of a given chain wheel $(n=24)$.

In addition to the $\delta_{A V R}$ MAX value, also the values of the standard deviation $S_{\delta}$ and the standard deviation of the average $S_{\delta x}$ were determined. On this basis, the uncertainty of the measurement for the level of significance $\alpha=0.05$ and $f=n-1=23$ degrees of freedom was calculated.

As a part of the wear tests conducted, plots of the Vickers hardness HV0.1 as a function of the distance from the surface were determined and the microstructure of the materials tested was established.

When conducting the wear tests of chain wheels in the presence of quartz abrasive, the abrasive was crushed between mating surfaces of the chain wheel and chain. After approx. 10 hours of operation, the intensity of crushing of the abrasive decreased distinctly, while the size of quartz grains was smaller than $20 \mu \mathrm{m}$. As a result of friction between mating elements, the temperature of the chain wheels increased, but not exceeded $55^{\circ} \mathrm{C}$.

\section{Results}

The microcutting with the loose abrasive of a significant hardness was the process responsible for destroying the surface of the contact zone. Linear scratches in a direction consistent with the movement of quartz grains in the friction pair are clearly visible in this figure. After the completion of the wear test, distinct signs of abrasion in the mating surfaces between the tooth and the chain were observed. In the case of chain wheels made of steel and ADI, abrasions were smooth without additional cavities. In turn, for chain wheels made of cast steel, single shallow cavities and cracks were found in the contact zone.

The materials tested can be compared (Table 6) with the linear wear $\delta_{A V R}$ MAX values determined. The $42 \mathrm{CrMo} 4$ and $34 \mathrm{CrNiMo6}$ surface-hardened steels were characterized by the lowest values of wear, while the highest values were obtained for the - L30GS and A6 structural cast steels. The ADI and the L35GSM, GS42CrMo4 and L20HGSNM alloy cast steels had intermediate values. 


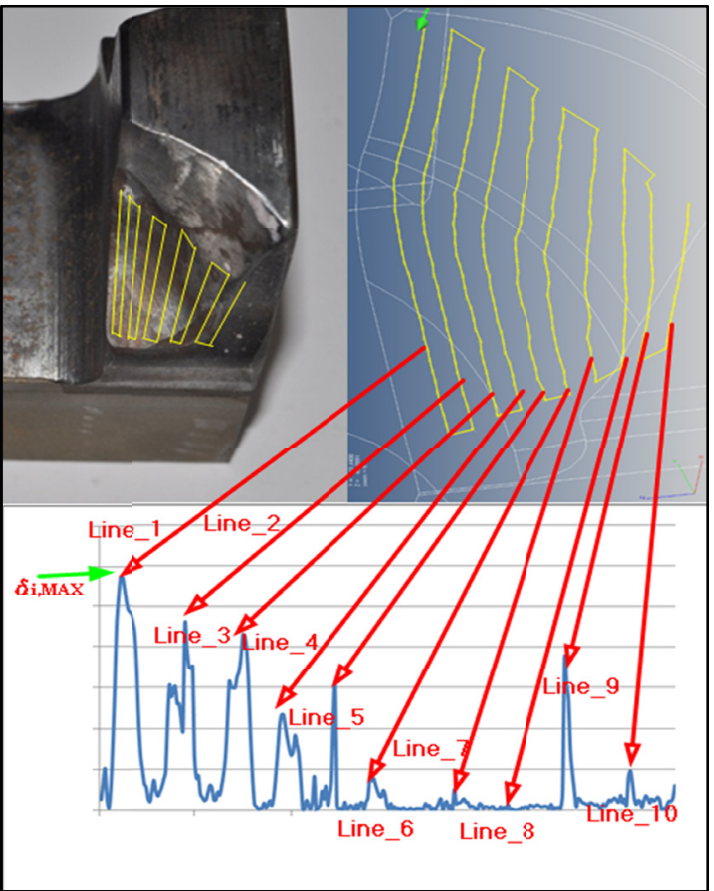

Fig. 2. The method of determining the wear parameters

However, more interestingly looks the presentation of the results obtained for linear wear $\delta_{A V R}$ MAX as a function of the strength (Fig. 3) and hardness of the surface subjected to operation (Fig. 4) in a breakdown into 4 groups of materials. When analysing individual groups of materials, it has been found that the structural cast steels are characterised by the lowest resistance, surface hardness and strength. The alloy steels subjected to surface hardening appeared to be materials with the highest wear resistance. Hard-wearing alloy cast steels were characterized by strength comparable to or greater than steel, while having a lower surface hardness at the same time.

TABLE 6

The values of the maximum linear wear $\delta_{A V R}$ MAX determined for the materials in question (measurement uncertainty determined for $f=N-1=23$ and $\alpha=0,05$ )

\begin{tabular}{|c|c|c|c|}
\hline \hline Designation of sample & $\boldsymbol{\delta}_{\boldsymbol{A V} \boldsymbol{R} \_\mathbf{M A X}}, \mathbf{m m}$ & $\boldsymbol{S}_{\boldsymbol{\delta}}, \mathbf{m m}$ & $\boldsymbol{S}_{\boldsymbol{\delta} \boldsymbol{x}}, \mathbf{m m}$ \\
\hline 42CrMo4 & $0,522 \pm 0,085$ & 0,202 & 0,041 \\
\hline 34CrNiMo6 & $0,62 \pm 0,13$ & 0,308 & 0,063 \\
\hline L30GS & $1,601 \pm 0,039$ & 0,283 & 0,019 \\
\hline L35GSM & $0,809 \pm 0,068$ & 0,164 & 0,033 \\
\hline GS42CrMo4 & $0,950 \pm 0,107$ & 0,194 & 0,052 \\
\hline A6 & $1,456 \pm 0,085$ & 0,199 & 0,041 \\
\hline L20HGSNM & $0,890 \pm 0,095$ & 0,226 & 0,046 \\
\hline ADI_240 & $0,934 \pm 0,118$ & 0,279 & 0,057 \\
\hline ADI_270 & $0,924 \pm 0,101$ & 0,238 & 0,049 \\
\hline ADI_310 & $0,800 \pm 0,076$ & 0,180 & 0,037 \\
\hline ADI_360 & $0,707 \pm 0,076$ & 0,183 & 0,037 \\
\hline
\end{tabular}

ADI with the upper ausferritic structure had wear properties and hardness of the operated surface similar to those of alloy cast steels, while cast irons with the lower ausferritic structure were characterised by wear and strength properties and hardness of the operating surface better than those of alloy cast steels. As compared with steels, ADI are characterized by a lower resistance to wear, while they have comparable or better strength properties.

After the wear tests, distributions of Vickers hardness HV 0.1 were determined in the zone of mating between the chain wheel and the chain as a function of the distance from the surface. The hardness plots were determined to a depth of $5 \mathrm{~mm}$. Up to this distance from the surface of the steels and cast steels tested, hardening of the top layer resulting from surface hardening was found. The parameters of these plots are summarized in Table 7.

TABLE 7

Comparison of the maximum hardness $\mathrm{HV}_{\mathrm{MAX}}$ and core hardness $\mathrm{HV}_{\mathrm{CORE}}$ values for the materials tested (measurement uncertainty determined for $f=N-1=4$ and $\alpha=0.05$ )

\begin{tabular}{|c|c|c|}
\hline Designation & HV $_{\text {MAX }}$ & HV $_{\text {CORE }}$ \\
\hline 42CrMo4 & $554 \pm 5$ & $468 \pm 5$ \\
\hline 34CrNiMo6 & $662 \pm 7$ & $514 \pm 5$ \\
\hline L30GS & $339 \pm 4$ & $318 \pm 4$ \\
\hline L35GSM & $488 \pm 5$ & $454 \pm 5$ \\
\hline GS42CrMo4 & $542 \pm 5$ & $473 \pm 5$ \\
\hline A6 & $442 \pm 5$ & $336 \pm 4$ \\
\hline L20HGSNM & $514 \pm 5$ & $464 \pm 5$ \\
\hline ADI_240 & $772 \pm 8$ & $606 \pm 6$ \\
\hline ADI_270 & $657 \pm 7$ & $536 \pm 5$ \\
\hline ADI_310 & $542 \pm 5$ & $425 \pm 4$ \\
\hline ADI_360 & $525 \pm 5$ & $409 \pm 4$ \\
\hline
\end{tabular}

The highest difference in the hardness is observed in the case of ADI_240, but the extent of the operating surface layer with changes in the hardness is the narrowest. For the variants of ADI 360 and ADI 310, the zone of the operating surface layer with the hardness changed in relation to the hardness of the core is much deeper as compared with the variants of ADI 240 and ADI_270. The results of the hardness measurements prove that the surface layer of the chain wheels made of ADI has strengthened due to the action of the abrasive - probably as a result of the transformation of retained austenite into martensite.

In the case of the group of steels and cast steels (except for the $34 \mathrm{CrNiMo6}$ steel) differentiated values of the HV0.1 hardness are observed in the range from 0 to $0.5 \mathrm{~mm}$. It is caused by the degrading action of the abrasive that could result in the occurrence of the zone of cracks in the surface layer which locally reduce the hardness.

The hardness of the $42 \mathrm{CrMo} 4,34 \mathrm{CrNiMo} 6$ steels and the L35GSM, GS42CrMo4, L20HGSNM alloy cast steels was similar. The $30 \mathrm{GS}$ structural cast steel was characterized by the lowest surface hardness that differed from the other iron alloys under consideration.

In the group of the austempered ductile irons, the surface hardness after the wear tests depends on the temperature of isothermal quenching - the hardness of the surface decreases along with an increase in the temperature. In the case of ADI, a characteristic plot of the hardness can also be noticed. It is 


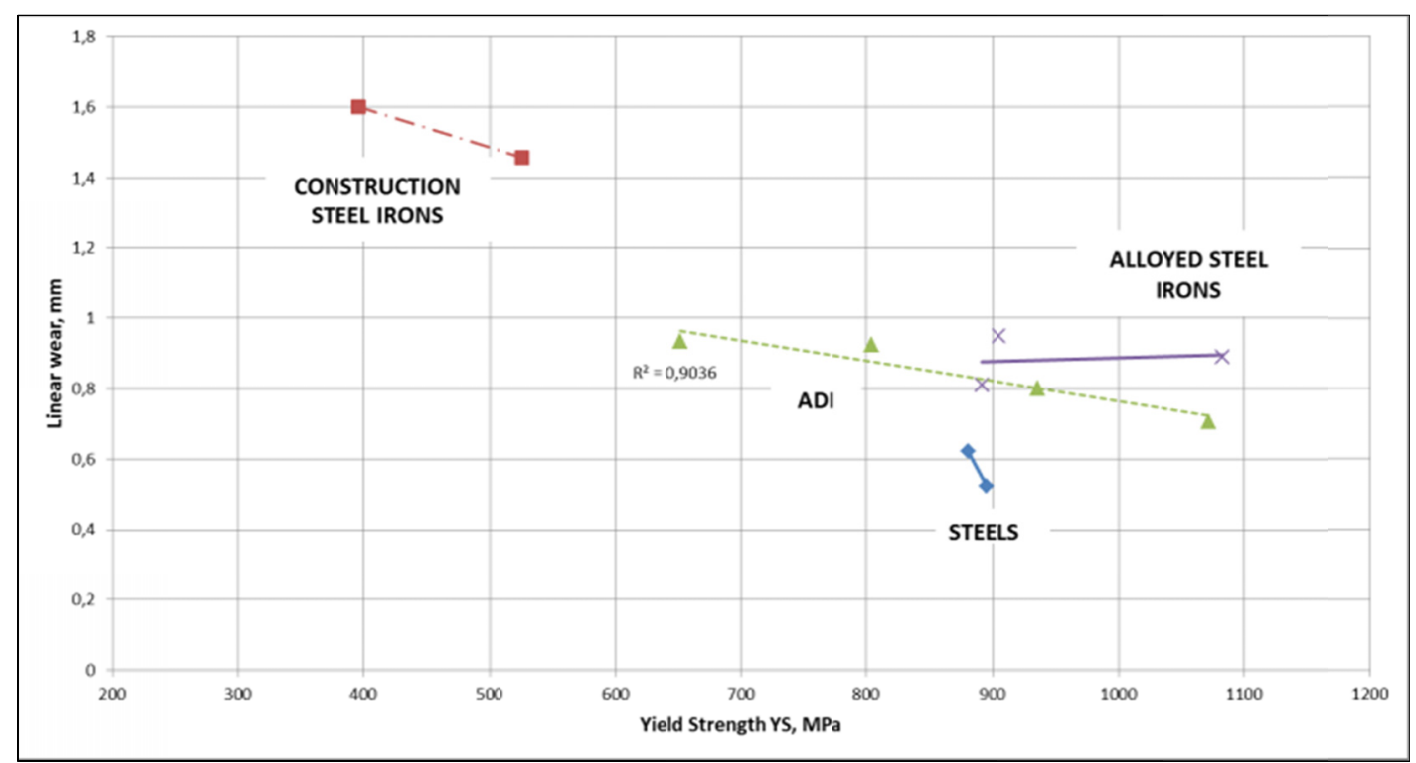

Fig. 3. Values of the linear wear for the material groups tested (steels, cast steels and ADI) as a function of the yield point

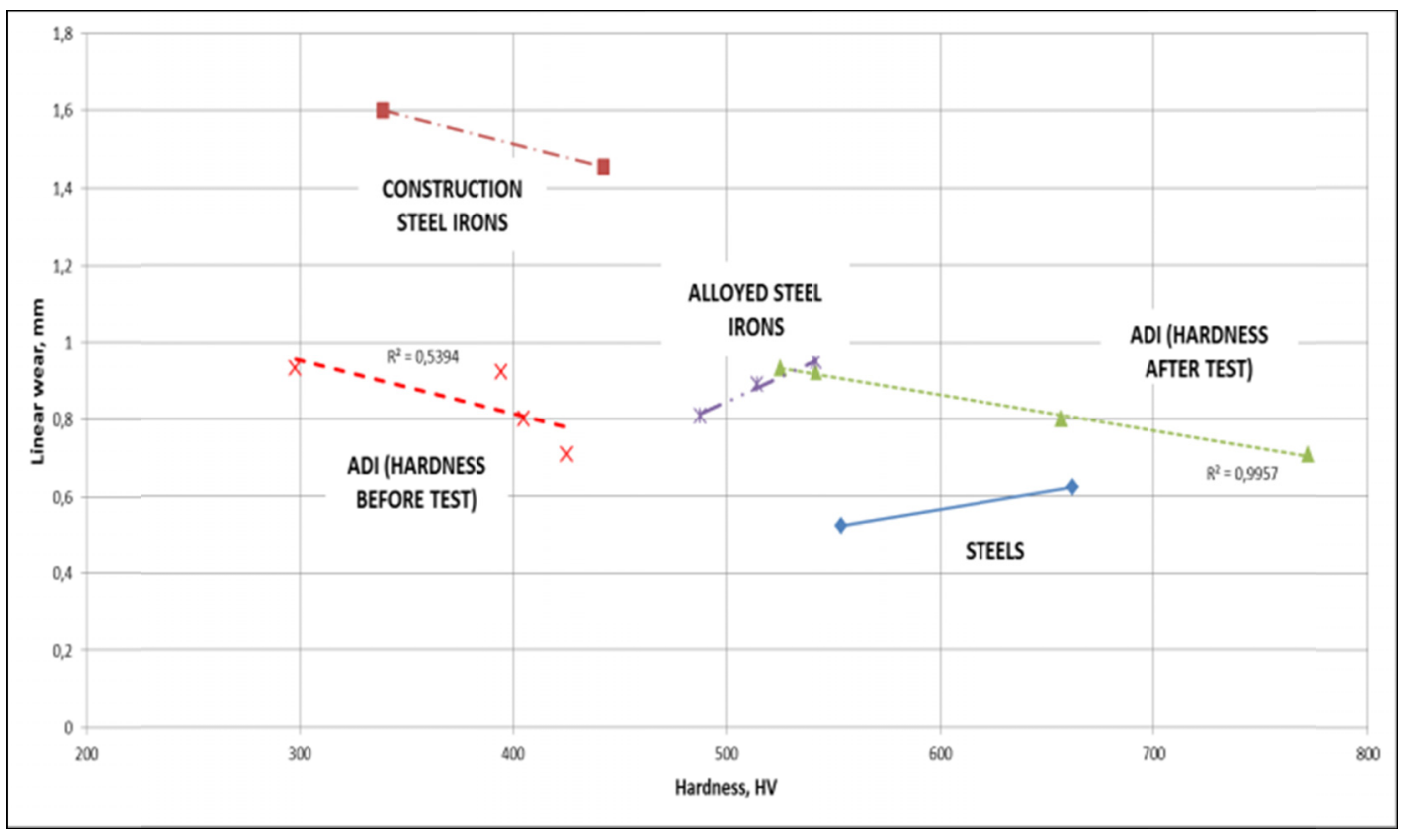

Fig. 4. Values of the linear wear for the material groups tested (steels, cast steels and ADI) as a function of the maximum surface hardness of HV0.1

characterized by the occurrence of a clear maximum in the surface layer. Differences of the $\mathrm{HV}_{\mathrm{MAX}}-\mathrm{HV}_{\mathrm{CORE}}$ hardness for all variants of the ADI also indicate the dependence on the isothermal quenching temperature.

The observations of the microstructure were performed using the OLYMPUS X70 optical microscope with $50 \times-1000 \times$ magnification. After the wear tests, samples for metallographic examinations were cut out from the area of mating between the chain wheel and the chain. Then the samples were ground, polished and etched with $2 \%$ Nital solution.

In the case of the $42 \mathrm{CrNiMo} 4$ and $34 \mathrm{CrNiMo} 6$ steels, the structure of martensite with a low content of austenite occurs in their surface layer. For the L20HGSNM, GS42CrMo4, A6, L30GS and L35GSM cast steels, the predominant structure of the surface layer consists of sorbite with martensite. Nodular graphite and upper ausferrite composed of bainitic ferrite and stable austenite can be identified in the structure of the ADI isothermally quenched at the temperature of $360^{\circ} \mathrm{C}$ (ADI_360). The total content of austenite was estimated at the level of $40 \%$. The structure of ADI_310 is composed of graphite and upper ausferrite, while the content of austenite is $27 \%$. The structure of ADI_270 and ADI_240 consists of nodular graphite and lower ausferrite composed of ferrite, trace amounts of martensite and low-carbon austenite. The content of austenite in ADI_270 is $20 \%$, while in ADI_240 - 12\%.

Numerous oblique cuts caused by the action the abrasive can be seen in the surface layer of the steels and cast steels. In the case of the GS42CrMo4 cast steel, a higher number of mi- 
crocuts can be noticed as compared with other materials. Alloy steels are characterised by a lower amount of surface damages as compared with cast steels.

In the case of ADI, single shallow cavities and the deformation of graphite nodules can be observed. Along with an increase of the austenite content in the cast iron, the degree of graphite deformation caused by the load and the action of the abrasive also increases.

This results from the properties of the matrix which becomes more vulnerable along with an increase in the content of retained austenite.

\section{Discussion}

The results of the measurements of the material and wear properties as well as the observations of the microstructure of the materials in question were presented in the previous section. These materials were represented by four groups of ferrous alloys: surface-hardened alloy steels, surface-hardened alloy cast steels for structural applications, hard-wearing surface-hardened alloy cast steels and austempered alloy cast irons. Surface-hardened alloy steels appear to be most resistant to the abrasive wear in conditions of the rolling and sliding form of contact. Hardwearing cast steels and ADI showed similar wear properties, but they were worse than those of steel, while cast steels for structural applications had the worst properties. The differences between the steels were inconsiderable and did not exceed $20 \%$. Hardwearing cast steels are characterized by a wear higher by $55-81 \%$ than that of the $42 \mathrm{CrMo} 4$ steel, while in the case of ADI this is approx. $35-79 \%$ higher. Structural cast steels wore significantly more intensively as compared with steel - the differences reached over $200 \%$.

As already mentioned, in the literature there is a significant

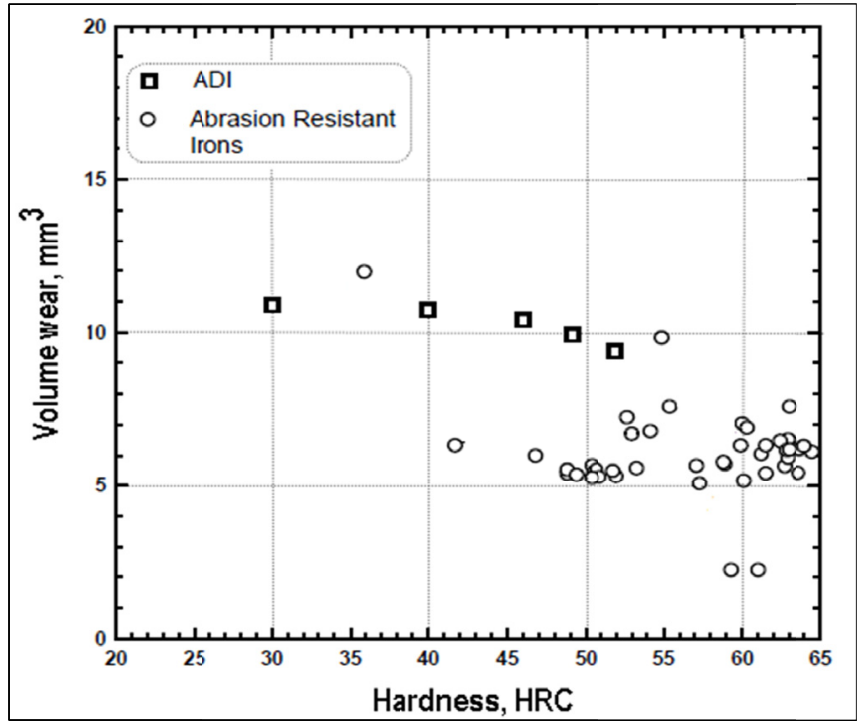

(a) number of works on wear properties of ADI, but only few of them present a comparison with other groups of iron alloys.

For example, the work [6] presents results of abrasive wear tests performed according to the method set forth in the ASTM G132-96 (2001) standard. Fig. 5a shows a portion of results of these tests relating to wear-resistant steels (there are no details regarding the tested materials in [4]) and ADI. It was observed that cast irons were characterized by an increased wear in relation to steels. The ratio of the linear wear values of the austempered cast irons to the linear wear values of steel ranges from 0.9 to 4.4 , but the highest amount of results is for values from 1.3 to 1.6 .

The work [20] presents the results of tests of the abrasive wear conducted on a disc-on-disc test rig (Fig. 5b). In the case of these tests, the ratio of the linear wear values of austempered cast irons to the linear wear values of the $34 \mathrm{CrNiMo} 6$ steel ranged from 0.6 to 1.7 .

When comparing the results obtained in this study for steels and ADI in conditions similar to the real ones with the results presented by other authors, it can be noted that they are generally consistent. Considering the fact that there are no test results for cast steels in the available literature, it is not possible to determine the similarity of the results obtained for this group of ferrous alloys.

It was demonstrated in the study that ADI had strengthened under the load, which manifested itself by an increase in the surface hardness (Table 7). After the wear tests, the surface hardness of cast irons with the lower ausferritic structure was comparable to or higher than that of alloy steels. However, the resulting increase in the hardness did not translate into increased wear resistance. This situation may be caused by greater heterogeneity of the structure of the cast iron surface layer as compared with the structure of steel. Fig. 6 shows the structure of the surface layers of the $42 \mathrm{CrNiMo} 4$ and $34 \mathrm{CrNiMo} 6$ steels.

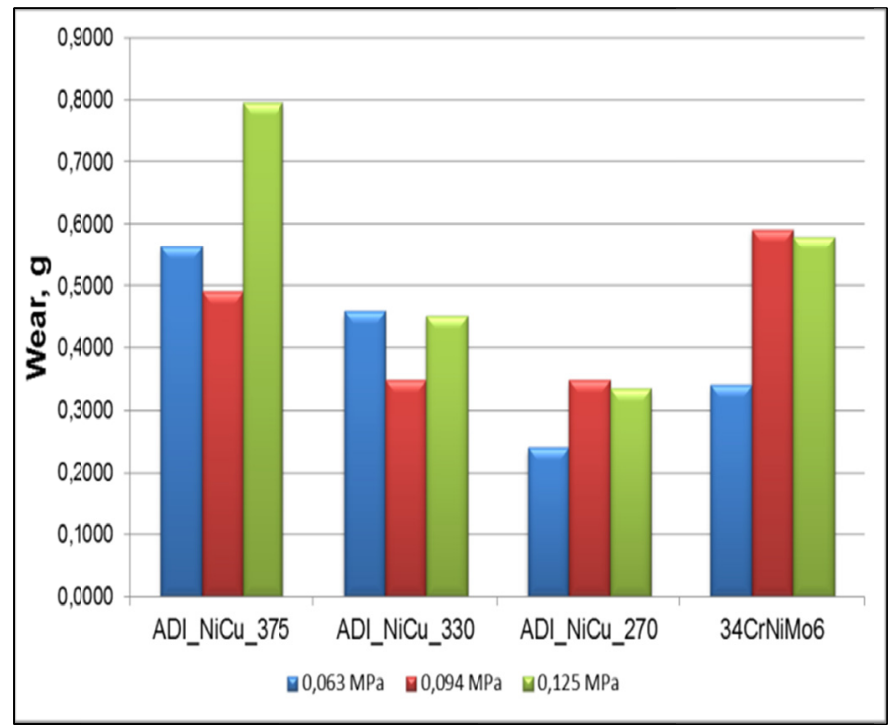

(b)

Fig. 5. The results of the wear tests: A. based on [4], B. based on [18] 
Homogeneity of the martensite structure can be observed. Only in the case of the $34 \mathrm{CrNiM}$ steel there occurs a small number of non-metallic inclusions that do not affect the wear properties. Traces of the action of the abrasive are shallow and oriented at an angle to the surface.

In the case of cast iron with the lower ausferritic structure (Fig. 7a and Fig. 7b), the presence of large inclusions is observed, which under the action of the abrasive are removed from the surface layer. Fairly deep gaps weakening the cast iron surface are formed then. Additionally, shallow oblique cracks can be seen (Fig. 7b and Fig. 7c). They resemble the cracks observed in steel. The graphite visible in Fig. 7c does not show any deformations under a load. Graphite nodules can also be removed as a result of the action of quartz grains. However, the resulting gap does not have a wedge shape that would facilitate the separation of the material as a result of cracking.

A different behaviour of graphite can be observed in the case of cast irons with the upper ausferritic structure. These cast irons are characterized by a high content of retained austenite. The initial spherical form of graphite (Fig. 8a) is transformed under the load into an elliptical or plate form (Fig. 8b and Fig. 8c) with a clear directionality. The deformed graphite is usually oriented at an angle of approx. 45 degrees in relation to the surface of

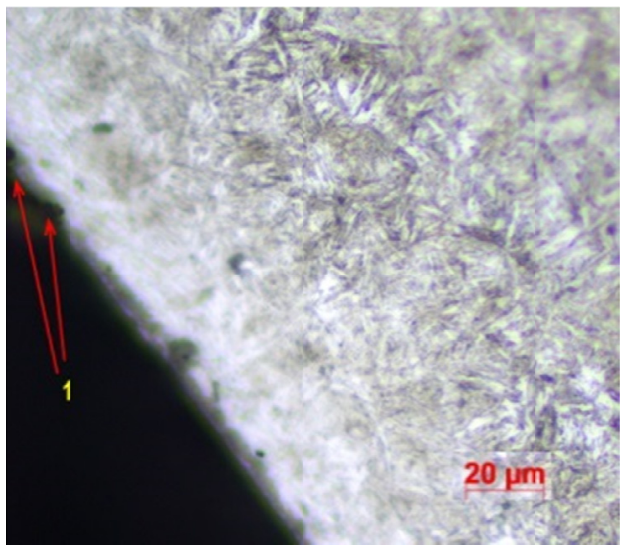

a) the material (Fig. 8c). As a result of the action of the abrasive, all soft graphite can be removed and a wedge-shaped gap can be created. Such a shape of the gap is conducive to formation of cracks and larger gaps. As a result of cracking, the shape of the cross section of the cut changes from wedge to triangular one.

The impact of cracking on wear properties of austempered cast irons was described in the work of Chawel et al. [21], in which it was noted that the cracking always began at the contact between graphite nodules and the matrix. It propagated into the material along the austenite and ferrite plates. Similarly, in the work of Tanaka et al, [22], based on the fatigue tests of nodular cast iron it was found that cracking began at the interface between graphite and the matrix and was caused by the stress concentration in the area where graphite occurs. In the work of Al-Ghonamy et al. [23] an increase in the wear of cast irons along with a reduction in the sphericity of graphite was found. This fact was explained by improved homogeneity of the matrix and reduced concentration of stresses in the case of the occurrence of spherical graphite. The phenomenon of cracking in the bainitic structure was described in detail in the work of Bhadeshia [24,25].

In the case of cast steels, the heterogeneity of the microstructure is observed in the top layer. It was caused by the presence of numerous inclusions, most likely associated with the

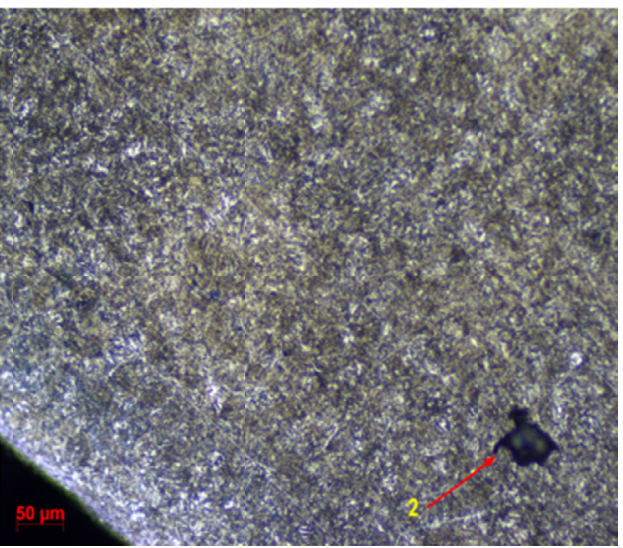

b)

Fig. 6. The microstructure of steel, A. 42CrMo4, B. 34CrNiMo6; 1 - scratches, 2 -inclusion

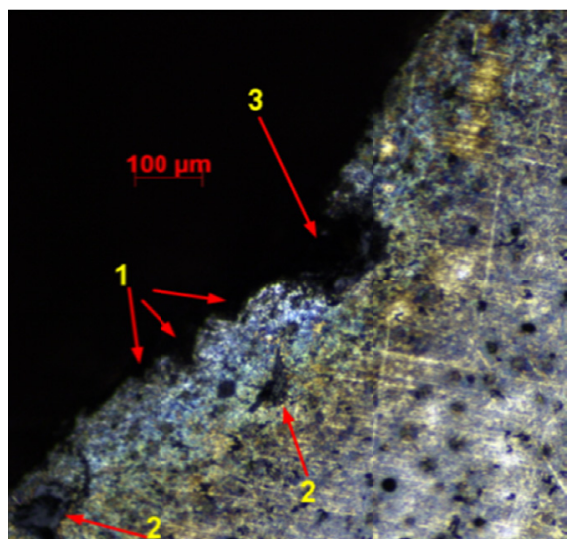

a)

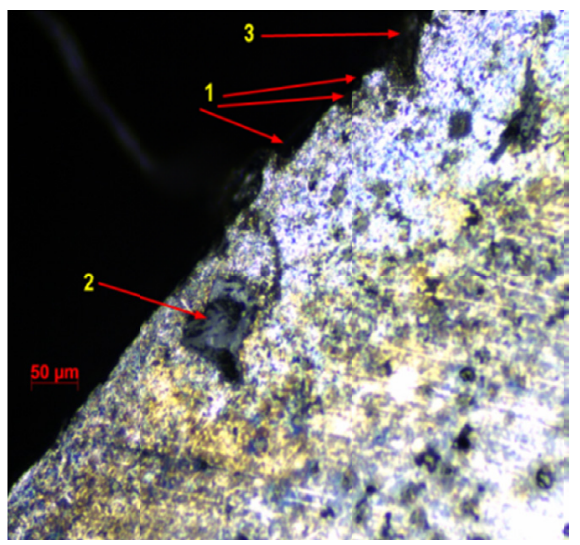

b)

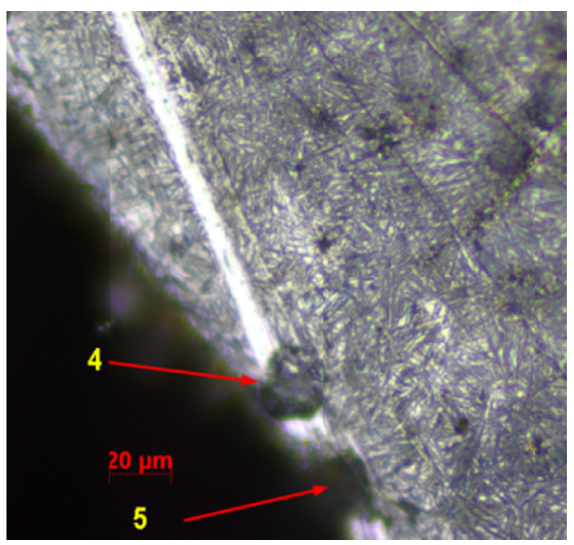

c)

Fig. 7. The microstructure of the ADI_240 cast iron; 1 - scratches 2 - inclusions, 3 - void after removal of an inclusion 4 - graphite, 5 - void after removal of graphite 


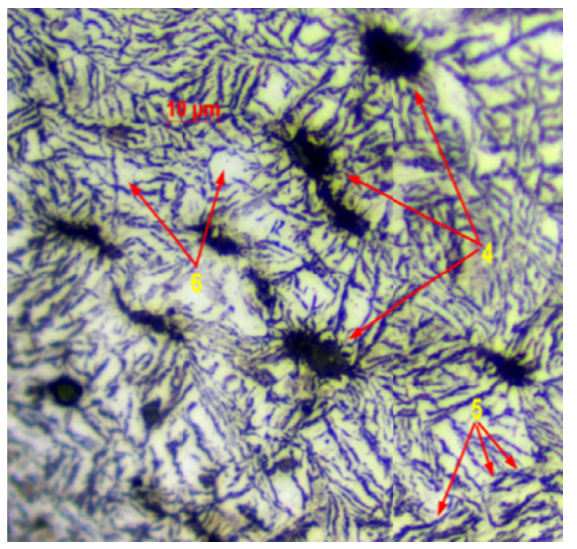

a)

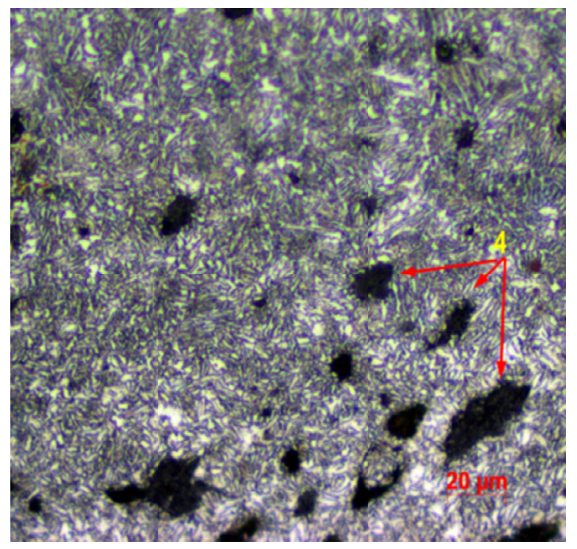

b)

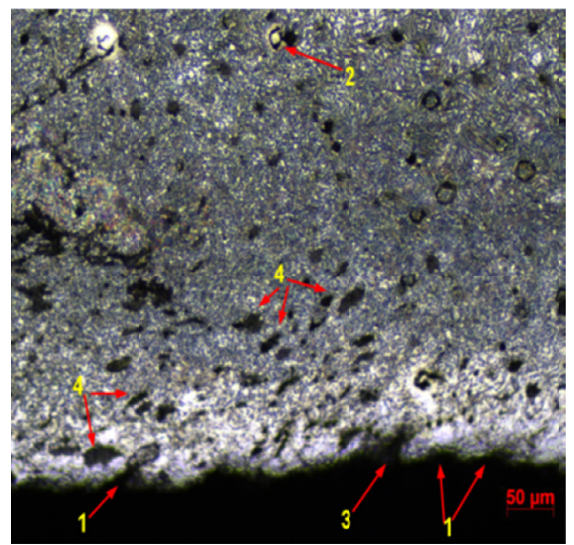

c)

Fig. 8. The microstructure of the ADI_360 cast iron; 1 - scratches, 2 - inclusions, 3 - void after removal of graphite, 4 - graphite, 5 - bainitic ferrite, 6 - retained austenite

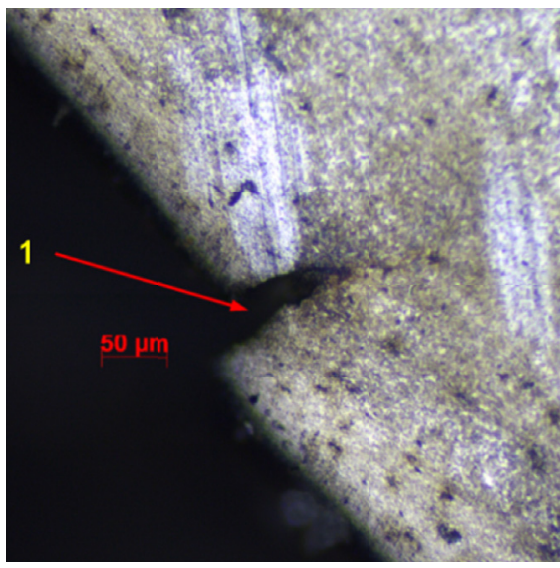

a)

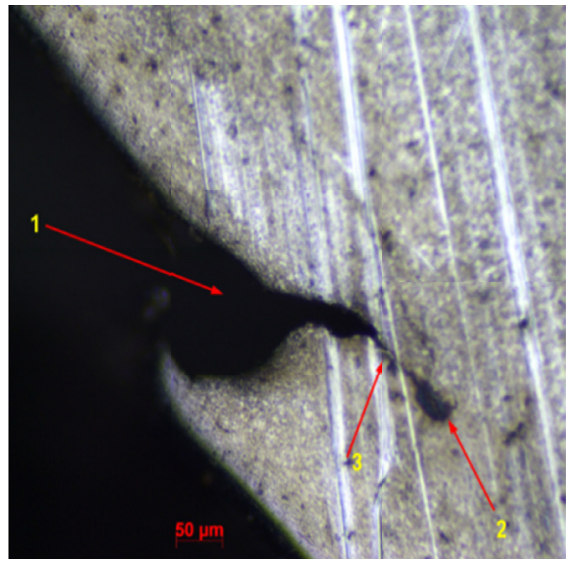

b)

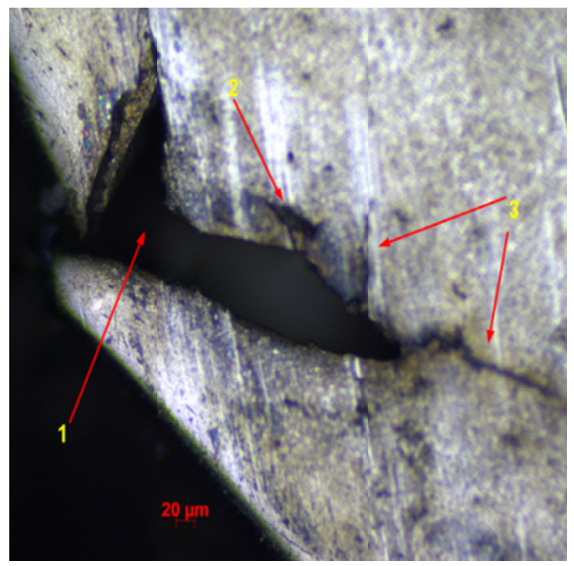

c)

Fig. 9. The microstructure of the GS42CrMo4 cast steel; 1 - microscratches, 2 - inclusions, 3 - cracking

casting process. An interesting view of the propagation of the damage to the surface of the GS42CrMo4 cast steel resulting from the action of the abrasive is presented in Fig. 9. The initial stage of damage is deep scratch oriented perpendicularly or at an angle to the surface (Fig. 9a). In a further stage of damage propagation there appear cracks that are connected with inclusions or other discontinuities in the structure (Fig. 9b) or crack oriented longitudinally and perpendicularly to the gap propagation (Fig. 9c). A further possible stage of damage is cracking of the remaining part of the material at its base.

\section{Conclusions}

1. On the basis of the wear test simulating the real operating conditions of chain wheels, it has been found in this study that surface-hardened steels, then ADI and hard-wearing cast steels have the most favourable wear properties, while structural cast steels are characterised by the least favourable wear properties.

2. Based on the hardness tests, it has been shown that during the operation of the chain wheels made of austempered ductile irons the surface may strengthen - most likely as a result of the transformation of austenite into martensite under a load.3. An observation has been made in this study that the wear of the surface in conditions of the rolling and sliding form of contact is significantly affected by the homogeneity of the structure of materials.

4. In the case of cast irons with the lower ausferritic structure, no graphite deformations occurred during the wear of the surface, while a significant deformation of graphite was observed for the cast irons with the upper ausferritic structure.

5. Deformed graphite in the ADI containing a large amount of retained austenite is oriented at an angle to the external surface, which facilitates the removal of the graphite by grains of the abrasive and causes extension of the cut.

6. In the case of the GS42CrMo4 cast steel, deep cuts caused by the action of the abrasive were observed - they initiated the propagation of cracks in the direction of non-metallic inclusions. 


\section{Acknowledgements}

The study was carried out as a part of the project "Innovative technology for production of tension members for transport systems with the use of cast materials", No. POIG.01.04.00-24-100/11.

\section{REFERENCES}

[1] M. Dolipski, P. Cheluszka, E. Remiorz, P. Sobota, Arch. Mining Sci. 60, 1, 25-38 (2015).

[2] M. Dolipski, E. Remiorz, P. Sobota, Arch. Mining Sci. 57, 4, 1101-1119 (2012).

[3] R. Burdzik, P. Folęga, B. Lazarz, Z. Stanik, J. Warczek, Archives of Metallurgy and Materials 57(4), 987-993 (2012).

[4] A.N. Wieczorek, Key Engineering Materials, 674, 201-206, (2016).

[5] A.N. Wieczorek, Management Systems in Production Engineering, 17, 28-34, (2015).

[6] K.L. Hayrynen, J.R. Keough, AFS Transactions 187, 1-10 (2005)

[7] A. Rimmer, W Bromwich, Gießereie-Erfahrungsaustausch 7+8, 7-9 (2004).

[8] E.P. Fordyce, C. Allen, Wear 135, 265-278 (1990).

[9] M. Nili Ahmadabadi, S. Nategh, P. Davami, Cast Metals 4, 188193 (1992).

[10] L. Ping, S. Bahadur, Wear 138, 269-284 (1990).

[11] D. Myszka, A. Wieczorek, Archives of Metallurgy and Materials 58/3, 967-970 (2013).

[12] K.L. Hayrynen, J.R. Keough, G.L. Pioszak, AFS Transactions, 1-15 (2010).
[13] D. Myszka, Technological aspects of deformation-induced transformation in austempered ductile iron Monograph Scientific Papers of the Warsaw University of Technology, Production Engineering 265, (2014).

[14] A.S.M.A Haseeb, Md Aminul Islam, Wear 244b, 15-19 (2000).

[15] J.M. Schissler, P. Brenot, J.P. Chobaut, Journal of Materials Science \& Technology 5, 71-77 (1987).

[16] A. Owhadi, J. Hedjazi, Davami, P., Journal of Materials Science \& Technology 14, 245-250 (1998).

[17] D. Myszka, A. Wieczorek, Material Engineering, 194/4, 332-335 (2013).

[18] Norm EN 1564:1997 - Founding. Austempered ductile cast irons.

[19] Technical Information OSMANIL E2.

[20] A. Wieczorek, Tribologia 1, 135-148 (2013).

[21] V. Chawla, U. Batra, D. Puri, A. Chawla, Journal of Minerals \& Materials Characterization \& Engineering 7/4, 307-316 (2008).

[22] Y. Tanaka, Z. Yang, K. Miyamoto, Material Transaction JIM 6, 749-756 (1995).

[23] A.I. Al-Ghonamy, M. Ramadan, N. Fathy, K.M. Hafez, A.A. El-Wakil, International Journal of Civil \& Environmental Engineering 10/3, 1-5 (2010).

[24] H.K.D.H. Bhadeshia, Journal de Physique IV 7, 367-376 (1997).

[25] H.K.D.H. Bhadeshia, Bainite in Steels, Institute of Materials, London, (2001). 